Raaijmakers, Tim; Van Oeveren, M. C.; Rudolph, Daniel; Leenders, V.; Sinjou, W. C. P.

\title{
Field Performance of Scour Protection Around Offshore Monopiles
}

Verfügbar unter / Available at:

https://hdl.handle.net/20.500.11970/100315

Vorgeschlagene Zitierweise / Suggested citation:

Raaijmakers, Tim; Van Oeveren, M. C.; Rudolph, Daniel; Leenders, V.; Sinjou, W. C. P. (2010): Field Performance of Scour Protection Around Offshore Monopiles. In: Burns, Susan E.; Bhatia, Shobha K.; Avila, Catherine M. C.; Hunt, Beatrice E. (Hg.): Proceedings 5th International Conference on Scour and Erosion (ICSE-5), November 7-10, 2010, San Francisco, USA. Reston, Va.: American Society of Civil Engineers. S. 428-439. 


\title{
Field Performance of Scour Protection Around Offshore Monopiles
}

\author{
T.C. Raaijmakers ${ }^{1}$, M.C. van Oeveren ${ }^{2}$, D. Rudolph ${ }^{3}$, V. Leenders ${ }^{4}$, W.C.P. Sinjou ${ }^{5}$ \\ ${ }^{1}$ Deltares | Delft Hydraulics, Rotterdamseweg 185, P.O. Box 177, 2600 MH Delft, \\ The Netherlands; e-mail:tim.raaijmakers@deltares.nl \\ ${ }^{2}$ Deltares | Delft Hydraulics, Rotterdamseweg 185, P.O. Box 177, 2600 MH Delft, \\ The Netherlands; e-mail:claire.vanoeveren@deltares.nl \\ ${ }^{3}$ Deltares | Delft Hydraulics, Rotterdamseweg 185, P.O. Box 177, $2600 \mathrm{MH}$ Delft, \\ The Netherlands; e-mail:daniel.rudolph@deltares.nl \\ ${ }^{4}$ Ballast Nedam Beheer B.V., Amersfoortsestraat 124d, P.O. Box 50, 3769 ZH \\ Soesterberg, The Netherlands; e-mail: v.leenders@ballast-nedam.nl \\ ${ }^{5}$ Ballast Nedam Beheer B.V., Amersfoortsestraat 124d, P.O. Box 50, 3769 ZH \\ Soesterberg, The Netherlands; e-mail:w.sinjou@ballast-nedam.nl
}

\begin{abstract}
Offshore Windpark Egmond aan Zee was installed in 2006 and is the first Dutch offshore windpark. To guarantee a fixed seabed level, dynamic scour protections were installed at all 36 monopiles. Since installation 251 multibeam surveys were executed to investigate the as-built stages and yearly performance of the dynamic scour protection. After 4 major storms the onset of deformation was observed around the monopiles: rocks within 1 pile diameter from the pile centre are displaced to a ring within 1-1.5 pile diameter from the pile centre. The majority of the deformation, however, was attributed to overall compaction of the armour layer. Performance parameters based on two design formulae were calculated for the actual occurred hydrodynamics and compared with the observed deformation. Both predictions performed well, although there are differences in the sensitivity to the hydrodynamic parameters. Consequently, the ranking of the severity of the storms was different for both approaches.
\end{abstract}

\section{INTRODUCTION}

The European offshore wind energy market is booming. In 2009 a growth rate of $54 \%$ was achieved. For 2010, a market growth of $75 \%$ is expected (press release $E W E A, 2010$ ). To establish such growth numbers, the wind energy market will have to focus more and more on cost efficiency, design optimization, flexible building methods and more reliable risk assessments. One relatively small, though important link in the chain of offshore wind park construction concerns the bed protection around the foundations to prevent scour development. Now, after a few years of operation of one of the first offshore windparks (the Dutch Offshore Windpark Egmond aan Zee, hereafter OWEZ), we have the opportunity to investigate the performance of the bed protection, which was designed on the basis of laboratory tests, in the field. 
OWEZ is located approximately 10 to 18 kilometres from Egmond aan Zee, off the Dutch coast, at water depths varying between 16 and 21 metres relative to MSL. It consists of 36 wind turbine generators (hereafter WTG) with a total capacity of 108 MW and an anticipated lifetime of 20 years. The foundations of the turbines consist of monopiles with an outer diameter of 4.6 meter.

In order to maintain the designed fixation level, scour protection was applied. The scour protection system comprises two layers: a granular filter layer and a dynamically stable armour layer, see Figure 1.

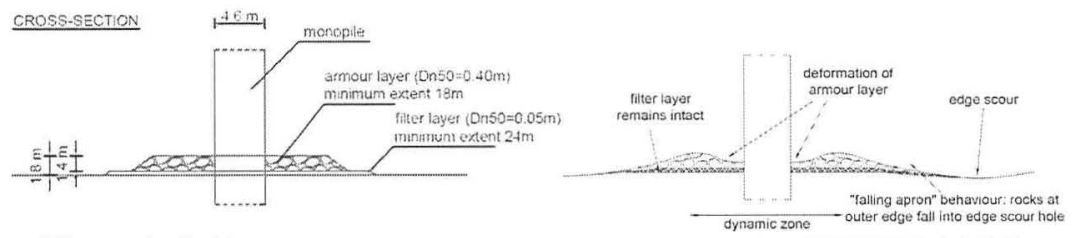

Figure 1: (left) scour protection layout for all 36 WTGs of OWEZ; (right) expected deformation pattern

Experiments were conducted to verify several conceptual protection layouts. In this laboratory test program it was found that the deformation of the scour protection followed a characteristic pattern as shown in the right plot of Figure 1. Some armour material is moved from close to the pile to a few meters away but does not disappear out of the vicinity of the pile. Just outside the scour protection edge scour develops. The scour protection behaves as a falling apron and partially rolls in the edge scour hole. The deepest edge scour hole develops at the downstream side of the main current direction. For the layout shown in Figure 1 , a lowering of the top level of the armour of about $0.4 \mathrm{~m}$ (range $0.3 \mathrm{~m}$ to $0.6 \mathrm{~m}$, depending on the location in the windpark) was predicted in case the 100 year design storm occurred. For the finally chosen design, an edge scour depth of 1-2m was expected, based on the interpretation of laboratory experiments and engineering judgement.

This paper focuses on design and performance of so-called dynamic scour protections around monopiles. The analysis is based on bathymetric surveys and hydrodynamic data at OWEZ (both measurements and operational models). In section 2 an overview of literature on scour protection for offshore wind parks is presented. Section 3 describes the as-built situation and performance of the scour protections on the basis of 251 bathymetric surveys, executed in the period 20062009. In section 4 the observations are correlated to the hydrodynamic climate. Also some prediction formulae for deformation of the scour protection are evaluated. Finally, in section 5 the conclusions and recommendations are presented. Although edge scour development is important in relation to burial depth of electricity cables and deformation of the edges of the scour protection, this topic is not further addressed in this paper. 


\section{LITERATURE ON SCOUR PROTECTIONS}

Some years ago some excellent books on scour (Whitehouse (1998), Sumer and Fredsoe (2002), Hoffmans and Verheij (1997)), were published. More recently, formulations for scour around monopiles in the marine environment were further improved (Raaijmakers, 2008) and time-dependent scour development around monopiles in field conditions can be predicted with reasonable accuracy (Rudolph, 2008). However, most of the times, the predicted scour depths are considered to be unacceptable. A scour protection is then required to guarantee a certain fixation level. Besides more innovative (and consequently not fully proven) techniques, like artificial frond mats, collars and gabions, the most reliable and scientifically proven method to protect the seabed is a protection consisting of loose rock. In general, the following types of rock protection are distinguished:

I. Static protection, in which the rocks in the armour layer are statically stable (i.e. do not move) during the design condition.

II. Dynamic protection, in which some stone movement is allowed as long as the structure will not fail. Three different types of dynamic protections can be identified:

IIa. Fully dynamic protection, in which the (usually small) rocks fully interact with the mobile seabed. During severe wave-dominated conditions rocks are picked up within the wave cycles and seabed sediment is washed out before the rocks fall back onto the seabed. Consequently, still a scour hole will develop, but the scour depth and timescale are smaller resp. larger than without the presence of bed protection.

IIb. Later installed dynamic protection, which is installed after a scour hole developed around the structure. The protection material is assumed to be sufficiently stable to prevent further scouring of the seabed.

IIc. Slightly dynamic protection, which is installed on the initial seabed and allows for evolving towards a dynamic profile as long as the deformation remains limited to the top layer.

A Type-I protection is installed at Horns Rev windfarm (Den Boon, 2004). Type-IIa protections are not very popular for wind turbines, since the fixation depth will vary in time, which results in varying resonance frequencies. In the offshore oil\&gas industry. Type-IIa protections are often applied for temporary drilling operations, where strict requirements are applied for the maximum stone size and scour development is acceptable as long as the penetration depth is not exceeded (Raaijmakers, 2007).

Type-IIb protections guarantee a constant fixation level after some time, when the scour protection is installed. The pile length of course has to accommodate for some scouring. However, because the top level of the protection is almost flush with the surrounding seabed, the loads on the protection are generally lower. Examples are Scroby Sands and Princess Amalia Windpark. At OWEZ, a Type-IIc protection is installed, which guarantees a fixed initial seabed level, the shortest possible pile length and the lowest possible burial depth for electricity cables. Since the scour protection protrudes approximately 2 to $3 \mathrm{~m}$ above the seabed, the 
hydrodynamic loads are somewhat larger. All types of rock protection usually are designed on the basis of the bed shear stress approach. A well-documented overview of design formulae is presented in De Vos (2008). Most formulae are available for current-only situations (e.g. bridge piers in rivers), but some formulae exist for wave-dominated conditions.

For offshore (wave-dominated) conditions, Den Boon (2004) and Whitehouse (2006) describe the OPTI-PILE design tool, which calculates a stability parameter:

$$
\mathrm{Stab}=\frac{\theta_{\max }}{\theta_{\mathrm{cr}}}
$$

in which $\theta_{\max }=$ maximum Shields parameter and $\theta_{\mathrm{cr}}=$ critical Shields parameter. From model tests it was found that for values of Stab $<0.415$ no movement of the stones in the scour protection occurred; for $0.415 \leq \mathrm{Stab}<0.460$ some movement occurred but no failure and for Stab $\geq 0.460$ the scour protection failed. Note that this failure criterion is not dependent on the applied rock volume, although applying a larger volume can still be a viable alternative: a larger deformation will occur during severe conditions, but this will not be problematic as long as the deformation is restricted to the scour protection.

De Vos (2008) presents a formula for a damage parameter $S_{3 D}$, which was fitted to 80 test results:

$$
\frac{S_{3 \mathrm{D}}}{N_{w}^{b_{0}}}=a_{0} \frac{U_{m}^{3} T_{m-1,0}^{2}}{\sqrt{g h_{w}}(s-1)^{3 / 2} D_{n 50}^{2}}+a_{1}\left[a_{2}+a_{3} \frac{\left(U_{c} / w_{s}\right)^{2}\left(U_{c}+a_{4} U_{m}\right)^{2} \sqrt{h_{w}}}{g D_{n 50}^{3 / 2}}\right]
$$

in which $\mathrm{N}_{\mathrm{w}}$ = number of waves, $\mathrm{U}_{\mathrm{m}}=$ wave orbital velocity at the seabed, $\mathrm{T}_{\mathrm{m}-1,0}=$ spectral wave period $\left(\mathrm{m}_{0} / \mathrm{m}_{1}\right), \mathrm{g}=$ gravitational constant, $\mathrm{h}_{\mathrm{w}}=$ water depth, $\mathrm{s}=$ specific density $\left(\rho_{\mathrm{s}} / \rho_{\mathrm{w}}\right), \mathrm{D}_{\mathrm{n} 50}=$ nominal stone diameter, $U_{\mathrm{c}}=$ depth-averaged current velocity, $\mathrm{w}_{\mathrm{s}}=$ particle fall velocity, $\mathrm{b}_{0}=0.24300, \mathrm{a}_{0}=0.00076, \mathrm{a}_{2}=$ $0.02200, a_{3}=0.00790, a_{4}=1$ for waves directed with the current and $a_{4}=U r / 6.4$ for waves opposing the current (Ur $=$ Ursell number). Coefficient $a_{1}=0$ for $\mathrm{U}_{\mathrm{c}} / \sqrt{ }\left(\mathrm{gD}_{\mathrm{n} 50}\right)<0.92$ and for waves directed with the current and $\mathrm{a}_{1}=1$ for $\mathrm{U}_{\mathrm{c}} / \sqrt{ }\left(\mathrm{gD}_{\mathrm{n} 50}\right) \geq 0.92$ or for waves opposite to the current.

This formula predicts deformation as function of number of waves. Because of the formula shape, deformation will never reach an equilibrium. However, many scour-related formulations predict development towards an equilibrium, as long as the layer characteristics remain constant (i.e. if the armour layer is not fully eroded). To be able to use this formula with the in-house developed software tool OSCAR (Offshore SCour And Remedial measures) for scour predictions, the left part of the formula of De Vos (2008) was slightly modified into: 


$$
\frac{S_{3 \mathrm{D}}}{N_{w}^{b_{0}}} \approx \frac{S_{3 \mathrm{D}}}{b_{1}\left[1-\exp \left(-\frac{N_{w}}{N_{\text {char }}}\right)\right]}
$$

which yields similar results within the range $N_{w}=1000-5000$ waves for which the original formula was fitted, when $b_{1}=7.6$ and the characteristic number of waves $\mathrm{N}_{\text {char }}=855$ waves. This latter value implies that deformation hardly increases after 2500-3000 waves and that equilibrium can be reached within one storm (compare $\mathrm{N}_{\text {char }}=630$ in Raaijmakers, 2007). Only a more severe storm will then be able to reshape the deformation pattern. Note that the De Vos-formula takes the current and wave magnitude and direction into account as well as the stone stability. The formula was fitted for an extent of 5 times the pile diameter $\mathrm{D}$ and a layer thickness of $2.5 \mathrm{D}_{\mathrm{n} 50}$. The rock volume, height of the protection and pile diameter are not taken into account.

\section{SURVEY ANALYSIS}

Multibeam echo sounding surveys were carried out before and after dumping of filter and armour material in 2006. Since 2007 annual surveys have been executed to check the performance of the scour protection. In 2007 at 20 of the 36 WTGs some additional scour protection was installed. In Table 1 an overview of all 251 available surveys is presented. From these surveys, the installed volumes of filter and armour (both initial in 2006 and additional in 2007) material were calculated.

Table 1: Overview of 251 available surveys (as-built and performance checks)

\begin{tabular}{|l|l|l|l|}
\hline $\begin{array}{l}\text { survey } \\
\text { ID }\end{array}$ & survey description & $\begin{array}{l}\text { avrg survey } \\
\text { date }\end{array}$ & $\begin{array}{l}\text { \# surveyed } \\
\text { WTGs }\end{array}$ \\
\hline SU01 & initial seabed & May 2006 & $33 / 36$ \\
\hline SU02 & out survey filter 2006 & June 2006 & $36 / 36$ \\
\hline SU03 & control survey 2006 & June 2006 & $3 / 36$ \\
\hline SU04 & in survey armour 2006 & July 2006 & $15 / 36$ \\
\hline SU05 & out survey armour 2006 & October 2006 & $36 / 36$ \\
\hline SU06 & check survey 2007 & June 2007 & $36 / 36$ \\
\hline SU07 & out survey additional installed armour & August 2007 & $20 / 36$ \\
\hline SU08 & check survey 2008 & May 2008 & $36 / 36$ \\
\hline SU09 & check survey 2009 & May 2009 & $36 / 36$ \\
\hline
\end{tabular}

The average levels within an area with a diameter of 4D are graphically presented in Figure 2. At the negative $y$-axis the average drop of the scour protection height between 2006 and 2009 is presented for each WTG. Despite some scatter, a weak correlation was found between installed volume (and thus larger obstruction height) and the level drop. The average armour layer thickness still ranges between 1.3 and $1.9 \mathrm{~m}$, which is about 3.6 to 5.3 stone layers. 


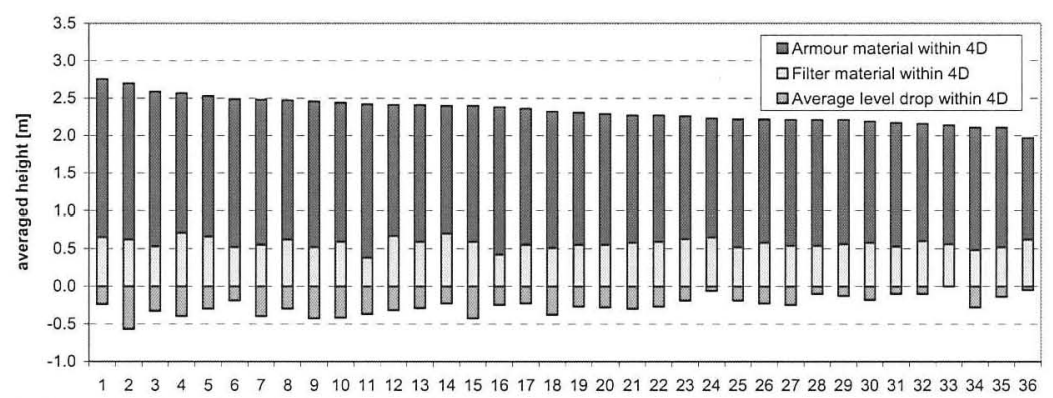

Figure 2: Installed volumes of filter and armour material and averaged bed level drop; WTGs sorted by total installed protection

Direct comparison between model tests and field data is often difficult, because in model tests scour protection layouts are 'perfectly' applied (constant extent and height), whereas the installation in the field is somewhat less accurate.

Often only a minimum layer thickness and extent are defined, which results in local surpluses of scour protection material, both in height and extent. Consequently, the deformation pattern around an individual WTG is very much dependent on the shape and volume of installed protection and it is difficult to draw conclusions on individual piles. Moreover, the correction for the vertical reference level in bathymetric surveys is often based on tidal elevations; an error in the order of $0.10 \mathrm{~m}$ is easily made. Since the OWEZ-scour protection is designed for a return period of 100 year, it is very likely that the observed deformations during less severe storms are of the same order as possible errors. Therefore, we translated all 36 surveys to one coordinate system (relative to the pile centre) and calculated z-levels relative to the initial seabed. Now we are able to average the results over WTGs that experienced a "similar history". In this way, local variations due to installation inaccuracies and errors in the vertical reference levels are levelled out. In Table 2 the subdivided pile groups are presented.

Table 2: Groups of WTGs with a similar history and therefore comparable

\begin{tabular}{|c|l|c|}
\hline groupID & description of group of WTG's & \#WTG's \\
\hline 1 & SU05 before 2006-storm and no additional armour in 2007 & 3 \\
\hline 2 & SU05 after 2006-storm and no additional armour in 2007 & 12 \\
\hline 3 & SU05 before 2006-storm and additional armour in 2007 & 9 \\
\hline 4 & SU05 after 2006-storm and additional armour in 2007 & 8 \\
\hline 5 & Armour surplus in SW-quadrant & 1 \\
\hline 6 & Filter initially installed NE of intended pile location & 1 \\
\hline 7 & Pile was installed before filter layer & 1 \\
\hline 8 & Only northern part of armour layer was initially installed & 1 \\
\hline
\end{tabular}

The total installed scour protection, the present state and the level changes between 2006 and 2009 are plotted for group 2 in Figure 3. It can be observed that 
the filter layer is indeed nicely installed within an area with diameter $6 \mathrm{D}$ and the armour layer within 4D. The middle graph shows a slightly deformed shape of the protection: a somewhat higher armour ring between a diameter of $2-4 \mathrm{D}$, with the highest peak at a diameter of 3D.
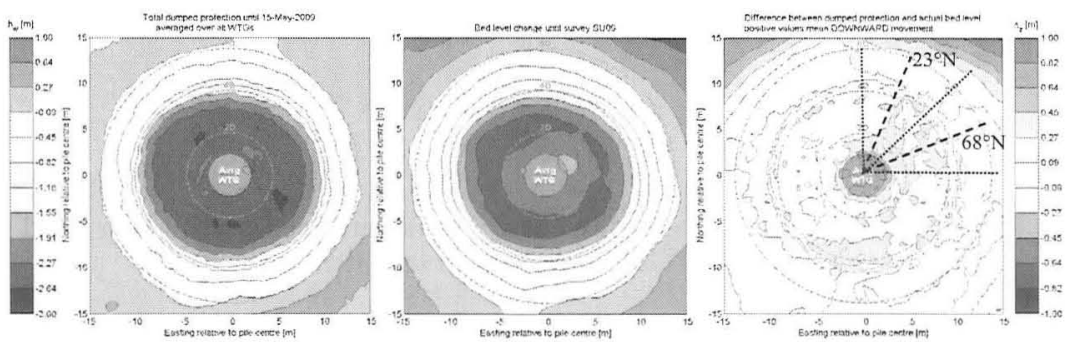

Figure 3: (left) total installed scour protection in 2006; (middle) present state of scour protection and surrounding seabed in 2009; (right) difference between total installed protection and present state; results are averaged over all 12 WTGs in WTG-group 2.

The right plot shows that in the area where the armour was located an average level drop occurred of about $0.25 \mathrm{~m}$. Close to the pile (within an area of 2D) this level drop was on average about $0.35 \mathrm{~m}$. These observations are also illustrated in Figure 4, which shows cross-sections averaged over $45^{\circ}$-"pie parts". The bold black line shows the $360^{\circ}$-average. Furthermore, all profiles show a local steep part at a distance of about $10 \mathrm{~m}$ from the pile centre, where some armour rocks at the edge of the armour protection were relocated towards the toe of the armour protection. Further away from the side slope of the armour layer, the height of the filter layer nearly remained constant, except for 'ray $23^{\circ}$ '. This is caused by edge scour development at the north-western side of the pile, which at OWEZ is downstream of the pile with respect to the flood current. The filter material acts as a falling apron as illustrated in Figure 1.

Because the bed level change is so evenly distributed over the armour layer, while the armour layer boundaries still remain rather confined, it seems more likely that the majority of the level changes is not caused by storm-induced reshaping of the protection. In the model tests, this evenly distributed level drop was not observed. Possible causes are compaction of the armour layer, settlement of the soil underneath due to the increased load and mixing of filter an armour material at the interface between the two layers, or a combination. The armour layer in the model tests was compactly installed, whereas installation with a backhoe in the field possibly resulted in a lower initial density and subsequent compaction during the first months. There was no evidence for loss of seabed sediment through the pores of the filter layer, since there was no deformation at locations where only filter material was present (see the area at a distance of $11-15 \mathrm{~m}$ from the pile centre, excluding 'ray $23^{\circ}$ ). Based on the above it was assessed that only about $0.10 \mathrm{~m}$ (on average, with locally larger deformation) of the average $0.35 \mathrm{~m}$ can be 
contributed to storm-induced deformation. The expected inverse correlation between deformation and water depth was too weak to be significant.

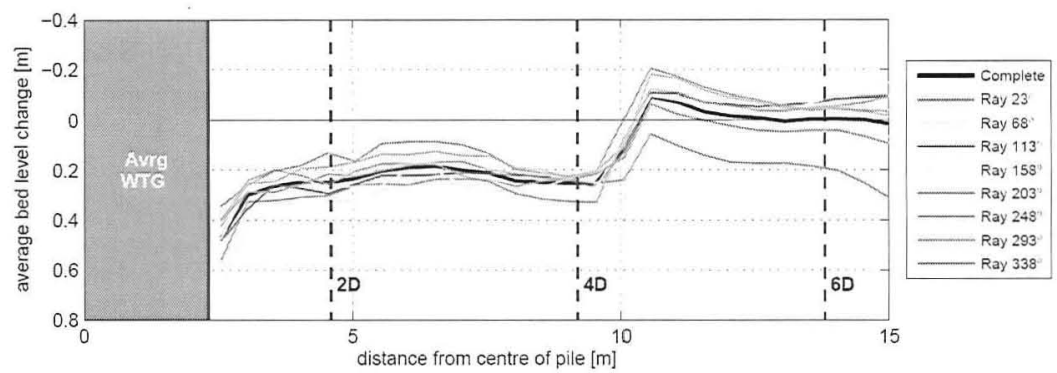

Figure 4: Cross-sectional profiles, averaged over $45^{\circ}$-"pie parts" and averaged over all 12 WTG's in group 2.

\section{HYDRODYNAMIC CLIMATE AND PERFORMANCE PREDICTION}

For the evaluation of the performance of the scour protection, a coherent data set consisting of time series of significant wave height $\left(\mathrm{H}_{\mathrm{s}}\right)$, peak wave period $\left(\mathrm{T}_{\mathrm{p}}\right)$, mean wave direction (MWD), water level elevation including tide and surge $\left(\mathrm{h}_{\text {tot }}\right)$, depth-averaged current velocity $\left(\mathrm{U}_{\mathrm{c}}\right)$ and current direction $\left(\mathrm{U}_{\mathrm{dir}}\right)$ was constructed from both measurements and operational models. Since the wave conditions are most important for deformation to the scour protection, only time series of the significant wave height are presented for illustrative purposes in Figure 5.

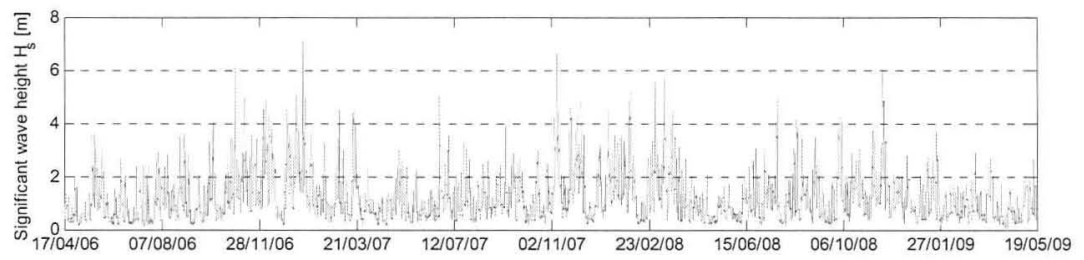

Figure 5: Time series of significant wave height during operational period (until survey SU09) at OWEZ

The most severe storms are presented in Table 3, which also shows the estimated return period for the significant wave height. Note that the time interval of the time series is only $10 \mathrm{~min}$, whereas the return periods are calculated on $3 \mathrm{hr}$ storm durations and for nearby measuring station "IJmuiden Munitiestortplaats" (YM6). 
Table 3: Storm occurrences between 2006 and 2009, based on $H_{s ; p e a k}>6.0 \mathrm{~m}$, which roughly corresponds to a return period of about $2.0 \mathrm{yr}$ at nearby measuring station YM6. Presented values are peak values and as such not representative for the storm duration.

\begin{tabular}{|c|c|c|c|c|c|c|c|}
\hline date & $\begin{array}{c}10 \mathrm{~min} \\
- \\
\mathrm{H}_{\mathrm{s}}[\mathrm{m}]\end{array}$ & $\begin{array}{c}3 \mathrm{hr}-\mathrm{H}_{\mathrm{s}} \text { at } \\
\text { YM6 } \\
{[\mathrm{m}]}\end{array}$ & $\begin{array}{c}\text { Return } \\
\text { Period } \\
\left(\mathrm{H}_{\mathrm{s}}\right) \\
{[\mathrm{yr}]}\end{array}$ & $\begin{array}{c}10 \mathrm{~min} \\
- \\
\mathrm{T}_{\mathrm{p}}[\mathrm{s}]\end{array}$ & $\begin{array}{c}\text { Stab }[-] \\
(\mathrm{OPTI}- \\
\text { PILE) }\end{array}$ & $\begin{array}{c}\mathrm{S}_{\text {eq: }} \\
\text { deVos } \\
{[\mathrm{m}]}\end{array}$ & $\begin{array}{c}\mathrm{S}_{\text {cum }}(\mathrm{t}): \\
\text { deVos }[\mathrm{m}]\end{array}$ \\
\hline $\begin{array}{c}01-11- \\
2006\end{array}$ & 6.11 & 6.87 & 11.1 & 16.7 & $\begin{array}{c}0.30- \\
0.36\end{array}$ & $\begin{array}{c}0.45- \\
0.76\end{array}$ & $\begin{array}{c}0.22- \\
0.38\end{array}$ \\
\hline $\begin{array}{c}18-01- \\
2007\end{array}$ & 7.12 & 5.97 & 2.0 & 11.1 & $\begin{array}{c}0.33- \\
0.42\end{array}$ & $\begin{array}{c}0.13- \\
0.24\end{array}$ & $\begin{array}{c}0.22- \\
0.38\end{array}$ \\
\hline $\begin{array}{c}09-11- \\
2007\end{array}$ & 6.64 & 6.43 & 4.6 & 16.7 & $\begin{array}{c}0.31- \\
0.37\end{array}$ & $\begin{array}{c}0.30- \\
0.51\end{array}$ & $\begin{array}{c}0.23- \\
0.40\end{array}$ \\
\hline $\begin{array}{c}21-11- \\
2008\end{array}$ & 6.07 & 6.56 & 5.8 & 11.1 & $\begin{array}{c}0.30- \\
0.37\end{array}$ & $\begin{array}{c}0.11- \\
0.27\end{array}$ & $\begin{array}{c}0.23- \\
0.40\end{array}$ \\
\hline
\end{tabular}

All relevant hydrodynamic parameters were then used to calculate values for the Stab-parameter (see Figure 6) and the predicted deformation according to the formulae by De Vos (see Figure 7). The calculated parameters in Table 3 are presented for a water depth range of $16-20 \mathrm{~m}$, in which the highest values correspond to the smallest water depths. When the Stab-parameters are compared with the critical Stab-values, it appears that the OPTI-PILE approach only predicts some deformation of the protection during the storm of 18 January 2007 and only at the shallowest WTG's.

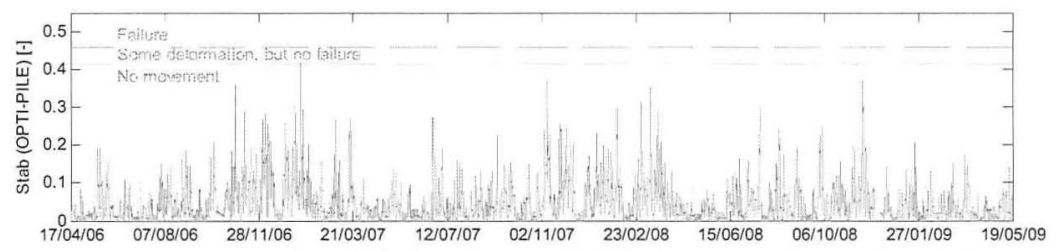

Figure 6: Time series of Stab-values at OWEZ for a water depth of $16 \mathrm{~m}$ (shallowest WTG-locations)

The conclusion from Figure 7 is somewhat different: the most severe storms occurred at 1 November 2006 and 9 November 2007, although both storms, even with an infinite persistence would not have caused failure of the bed protection. The difference between both formulations is caused by the sensitivity to wave height and wave period. The OPTI-PILE approach takes both parameters into account via the Stab-parameter, in which the wave height is most influential. The presence of the monopile is only accounted for by means of fitting of the critical Stab-values. The hydrodynamic load on the stones around a monopile, however, is also strongly influenced by the type and strength of vortices that are caused by the interaction between hydrodynamics and structure. 
The dimensionless Keulegan-Carpenter number $\left(\mathrm{KC}=\mathrm{U}_{\mathrm{m}} \mathrm{T} / \mathrm{D}\right)$ is a good measure to account for interaction between structure and (wave-induced) hydrodynamics. For $\mathrm{KC}<1$ hardly any vortices occur; for $1<\mathrm{KC}<6$ the lee wake vortices are dominant, while for $\mathrm{KC}>6$ horseshoe vortex development starts. For a given pile diameter $\mathrm{D}$, the hydrodynamic load by vortices is, thus, strongly related to the wave period. This effect is not incorporated in the OPTI-PILE approach.

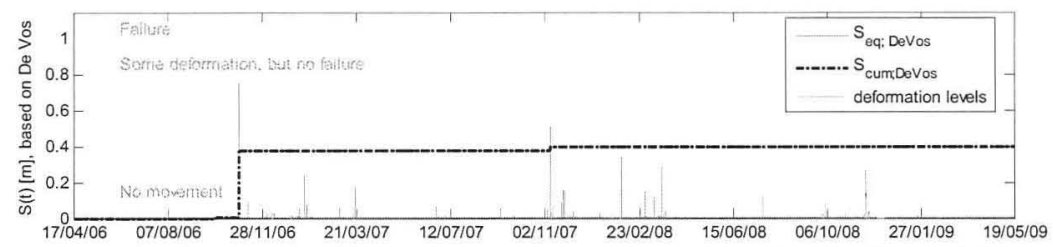

Figure 7: Time series of predicted deformation, according to the slightly modified formula of De Vos.

The approach of De Vos attributes much more weight to the wave period (a power of 2 on the wave period and also through the bed orbital velocity). Although the physical basis for the shape of this formula is not so obvious, this formula implicitly takes the $\mathrm{KC}$-effect into account (through the wave period). The pile diameter is not a variable in the formula, probably because the pile diameter was not varied in the test program to which the formula was fitted. The formula is therefore expected to perform less well for different $\mathrm{D} / \mathrm{h}_{\mathrm{w}}$-ratios (and hence a different $\mathrm{KC}$-range).

When the blue lines in Figure 6 and Figure 7 are compared, the sensitivity to the wave period is probably underestimated in the OPTI-PILE approach, while it seems to be somewhat overestimated in the approach of De Vos. It appears that the KC-numbers during the storms of 1 November 2006 and 9 November 2007 were outside the tested range of De Vos. It is therefore not unlikely that the strong dependency on the wave period that was found for the $\mathrm{KC}$-range between 1 to 3 weakens for larger $\mathrm{KC}$-numbers.

Based on the analysis of the performance of both formulae, currently a new formula is being developed that includes the stone stability (through the Stabparameter), the structure-induced vortex pattern (through the $\mathrm{KC}$-number), the time effect (number of waves), the obstruction height of the protection (ratio $h_{\text {obs }} / h_{w}$ ) and the effect of a superimposed current (through the relative velocity and the direction between current and waves).

\section{CONCLUSIONS}

In summer/autumn 2006, the 36 monopile foundations of the Egmond windpark were protected with a dynamic scour protection. Since installation in 2006,4 major storms have occurred with a return period of more than 2 years. The observed deformation from bathymetric surveys was assessed to be mainly related to (a combination of) compaction of the armour layer due to cyclic loading, settlement of the underlying soil and mixing of filter and armour material at the 
interface between filter and armour layer (average $0.25 \mathrm{~m}$ ). Storm-induced deformation, resulting in a somewhat higher ring of armour stones at a distance of 1-2D from the pile centre, could be observed in the surveys. The storm-related part of the level drop close to the pile ranged between 0 and $0.4 \mathrm{~m}$ (average $0.10 \mathrm{~m}$ ).

Two formulations (OPTI-PILE and De Vos) were verified against the observations and the deformations all were in the range of the formula predictions, considering the relatively large spread. However, the sensitivity to the wave period was rather different for the two approaches, especially for large $\mathrm{KC}$-numbers. Consequently, the ranking of the severity of the storms was different for both formulae.

For scientific reasons, a storm with a return period closer to the design value would be of interest to extend the verification to "near-failure" situations. Finally, it is concluded that the scour protection behaviour is according to expectations from the model tests at a scale of $1: 40$, which confirms that model testing is a suitable method for verification of conceptual layouts and design optimisation for dynamic scour protections.

\section{ACKNOWLEDGEMENTS}

The authors are thankful to the Dutch Ministry of Economic Affairs for cofinancing this research project. Furthermore we would like to thank the contractor Bouwcombinatie Egmond (joint venture of Ballast Nedam and Vestas) and the owner Noordzeewind (a 50/50 joint Venture of Shell and NUON) for providing all bathymetric surveys.

\section{REFERENCES}

Boon, J.H. den, Sutherland J., Whitehouse R., Soulsby, R., Stam, C.J., Verhoeven, K., Hogedal, M., Hald, T. (2004). "Scour behaviour and scour protection for monopile foundations of offshore wind turbines". Proc. European Wind Energy Conference. London 2004.

Hoffmans, G.J.C.M., Verheij, H.C. (1997). "Scour Manual”. Balkema, Rotterdam, The Netherlands.

Raaijmakers, T.C., Rudolph, D. (2007). "Scour protection of spud cans - a new design approach". Proc. of Eleventh Intl. Conference "The Jack-up Platform", Design Construction and Operation. London, 2007.

Raaijmakers, T.C., D. Rudolph, (2008). Time-dependent scour development under combined current and waves conditions - laboratory experiments with online monitoring technique. Proc. 4th Intl. Conference on Scour and Erosion, Tokyo, Japan

Rudolph, D., Raaijmakers, T.C., Stam, C.J.M., (2008), "Time-dependent scour development under combined current and wave conditions - hindcast of field measurements". Proc. 4th Intl. Conference on Scour and Erosion, Tokyo, Japan, 2008

Sumer, B.M., Fredsce, J (2002). "The mechanics of scour in the marine environment". Advanced Series on Ocean Engineering - Volume 17. New Jersey: World Scientific. 
Vos, L. de, (2008). "Optimisation of scour protection design for monopiles and quantification of wave run-up - Engineering the influence of an offshore wind turbine on local flow conditions". PhD Thesis Ghent University.

Whitehouse, R.J.S. (1998), Scour at marine structures. London: Thomas Telford Ltd.

Whitehouse, R.J.S., Sutherland, J., O'Brien, D. (2006). "Seabed scour assessment for offshore windfarm". Proc. of Third Intl. Conference on Scour and Erosion, Amsterdam, The Netherlands. 